\title{
Shape memory textiles - technological background and possible applications
}

\author{
Guido Ehrmann ${ }^{1}$, Andrea Ehrmann ${ }^{2, *}$ \\ ${ }^{1}$ Virtual Institute of Applied Research on Advanced Materials (VIARAM) \\ ${ }^{2}$ Working Group of Textile Technologies, Faculty of Engineering and Mathematics, Bielefeld University of Applied \\ Sciences, Bielefeld, Germany \\ *Corresponding author E-mail address: andrea.ehrmann@fh-bielefeld.de
}

\section{INFO}

CDAPT, ISSN 2701-939X

Peer reviewed article

2021, Vol. 2, No. 2, pp. 162-172

DOI 10.25367/cdatp.2021.2.p162-172

Received: 23 November 2021

Accepted: 05 December 2021

Available online: 16 December 2021

\begin{abstract}
While shape memory alloys (SMAs) and shape memory polymers (SMPs) can already be found in diverse applications, shape memory textiles are less often used. Nevertheless, they are regularly investigated. Typical ways to produce shape memory textiles (SMTs) are introducing shape memory wires, printing shape memory polymers on them (" $4 D$ printing"), or using textile materials such as poly(lactic acid) (PLA) which show shape memory properties on their own. This review gives a brief overview of these technological possibilities and possible applications of shape memory textiles.
\end{abstract}

\section{Keywords}

shape memory properties,

3D printing,

polyurethane,

wrinkle-free,

design,

stimulus,

smart textile,

recovery

(c) 2021 The authors. Published by CDAPT.

This is an open access article under the CC BY-NC-ND license https://creativecommons.org/licenses/ peer-review under responsibility of the scientific committee of the CDAPT.

\section{Introduction}

The shape memory effect describes the situation that a material can be deformed and recover its original shape due to an external stimulus, e.g. by heat, light or chemical modifications of their environments [1]. Typical applications of shape memory polymers (SMPs), shape memory alloys (SMAs) or shape memory ceramics (SMCs) can be found in biomedicine [2-4], spacecraft [5], soft robotics [6,7] or also smart textiles $[8,9]$.

Shape memory materials can be found in diverse shapes, from bulk to thin films to fibers or foams [1012]. Another special possibility to use shape memory materials is 3D printing [13]. In this context, shape memory polymers are often used to enable easier printing and folding the desired structure afterwards [14]. This technique as well as printing objects with alternating shapes, triggered by different stimuli, is often called "4D printing", with time as the fourth dimension [15-17]. 
While 3D printing on textile fabrics belongs to the emerging research topics of our time [18-22], combinations of 4D printing with textile fabrics are nevertheless scarce. Similarly, shape memory textiles in general are not investigated very often. Fig. 1 shows the numbers of hits in the Web of Science for both topics. While the wordings "4D printing" or "4D textiles" seem to become more often used, there is no such trend visible for the technical term of shape memory textiles.

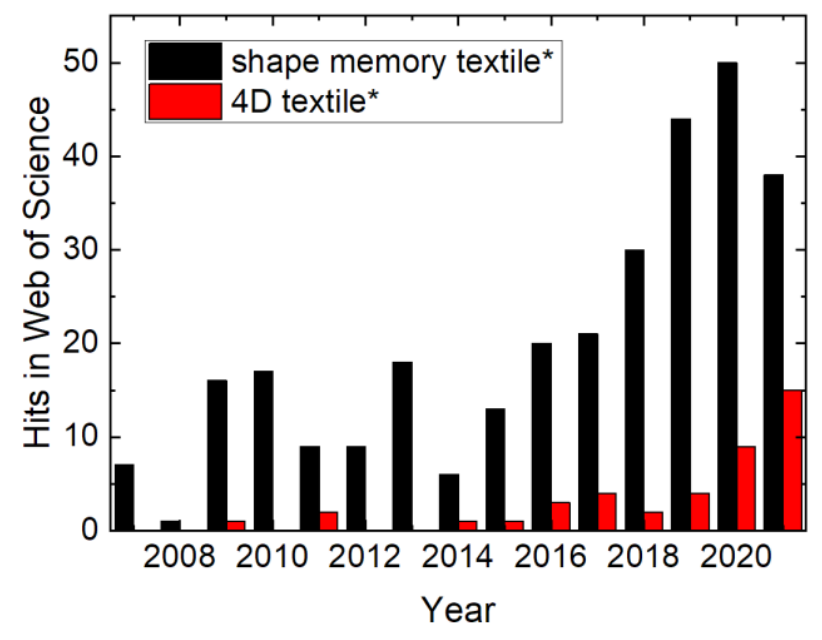

Fig. 1 Hits in the Web of Science for chosen search phrases. Data taken on November 21, 2021.

Here we give an overview of shape memory textiles, produced either by using SMPs for the fabric construction, integrating shape memory materials or using 3D printing or other coating method to apply a shape memory layer.

\section{Shape memory textiles produced by shape memory fibers}

Several polymers show shape memory properties alternating soft and hard parts in the polymer chain, such as poly(lactic acid) which is often used in 3D printing by the fused deposition modeling (FDM) technique [23-25], polyurethanes (PUs) [26-28] and others. This offers the possibility to produce polymer fibers with shape memory properties by different spinning methods, often by melt-spinning [29] or also by electrospinning [30,31], which can be processed further into a yarn and finally into a textile fabric or directly into a nonwoven.

This is why the production of shape memory fibers belongs to the often reported techniques to prepare shape memory textiles. Meng et al., e.g., used wet spinning to prepare shape memory polyurethane fibers with poly(caprolactone) segments [32]. The switching temperature of these fibers was $36{ }^{\circ} \mathrm{C}$, i.e. quite near the temperature of the body interior, enabling interesting applications in smart clothes. They found a high recovery ratio of more than $95 \%$ under cycling thermal drawing and recovery. The group also compared wet and melt spinning of this material and found the latter to result in higher tenacity, breaking strain and shape memory effect in comparison with wet-spun shape memory fibers [33]. Besides, they reported on the influence of different heat treatments of melt-spun shape memory fibers at different temperatures, leading to differently improved mechanical and SME properties [34].

Kumar et al. also used polyurethane as shape memory polymer and produced filaments by melt spinning [35]. They found a glass transition temperature of approx. $30^{\circ} \mathrm{C}$, i.e. closer to the body surface temperature. By combining this filament with nylon, they prepared a yarn which was circularly knitted to produce smart compression stockings. The pressure exerted by these stockings onto a patient's leg increased with increasing activation temperature, enabling such materials as smart wound care products or the like, e.g. by applying dynamic pressure by a programmed heating stimulus $[36,37]$.

Jin and $\mathrm{Hu}$ produced a core-spun yarn by ring-spinning and friction spinning with wet-spun shape memory core fibers and a cotton roving as the covering material [38]. These yarns were woven into twill 
fabrics with pure cotton warp yarn and the shape memory core yarn in the weft. The switching temperature was identified as $58{ }^{\circ} \mathrm{C}$. Interestingly, they found shape memory effects even in the warp direction of the fabric under cyclic loading and recovery and a higher SME in the ring-spun yarns than in the friction-spun ones.

Wet-spinning was also used by Ji et al. to produce SME fibers from polyurethanes with different hardsegment contents and compared them with thin films of the same materials [39]. They reported less shape fixity of the fibers, but higher shape recovery in comparison with the thin films.

Sáenz-Pérez et al., on the other hand, used melt spinning to prepare different PU fibers with shape memory effect and producing plain knitted structures from them [40]. They found very high shape recovery ratios of mostly more than $99.9 \%$ with glass transition temperatures around $37-38{ }^{\circ} \mathrm{C}$ for the self-prepared fibers and around $52{ }^{\circ} \mathrm{C}$ for a commercial material tested in comparison.

Similarly, Walczak et al. prepared melt-blown fibers from poly(L-lactide) (PLLA) blended with atactic poly(hydroxybutyrate) (a-PHB) [41]. They obtained a high shape recovery for a nonwoven prepared from this material and concluded that blending of PLLA with a-PHB significantly reduced the glass transition temperature from $65^{\circ} \mathrm{C}$ to $38^{\circ} \mathrm{C}$, making the new polymer blend highly interesting for self-fixing and selfadjusting implants, graft anchors, or other biomedical purposes.

Such biomedical applications necessitate biocompatibility. Preparing polyurethane fibers by wet spinning, Meng et al. concentrated on the evaluation of the cytotoxicity, hemolysis, sensitization, and dermal irritation and found none of these potential problems to occur, making such shape memory fabrics indeed highly interesting for biomedicine [42].

Besides pure polyurethanes and PLA or PLLA, there are also more complex polymers and blends used as shape memory fibers. Meng et al. combined PU with multiwall carbon nanotubes (MWCNTs) to produce melt-spun fibers [43]. While spinning became more complicated with increasing MWCNT content, lower concentrations resulted in homogenous distribution and alignment and correspondingly high tenacity and initial modulus as well as increased recovery ratio and recovery force. On the other hand, Deng et al. prepared polyurethane SMFs which they coated with a sheet of carbon nanotubes (CNTs) to prepare a shape-memory supercapacitor in combination with a gel electrolyte [44].

Another polymer investigated as a possible shape memory fabric is poly(trimethylene terephthalate) (PTT), a semi-crystalline thermoplastic polymer [45]. Zhao et al. suggested this material for fashion design. Interestingly, recovery at different temperatures between $20^{\circ} \mathrm{C}$ and $60{ }^{\circ} \mathrm{C}$ resulted in similar crease recovery ratios in spite of the glass transition temperature being between $40{ }^{\circ} \mathrm{C}$ and $60{ }^{\circ} \mathrm{C}$, which the authors attributed to the low crystallinity of the PTT filament. On the other hand, a high crease recovery rate could be reached by simulated ironing and hand stroking, as it is easiest used for crinkled clothes.

Lu et al. suggested covalently crosslinked poly(acrylamide) (PAAm) and ionically crosslinked carrageenan, forming a hydrogel with high elongation up to a factor of 20 [46]. By stretch-drying these stretched hydrogels, fibers were formed with shape memory properties similar to their wet state.

Quite an unexpected shape memory effect was found by Zhu et al. in cellulose/chitosan multifilament fibers [47]. The fibers were spun from a new solvent from $\mathrm{LiOH}, \mathrm{KOH}$ and urea aqueous solution and showed a two-switch shape memory behavior under stimulation with water and acid due to changing the self-aggregation force between both partners in the blend.

Besides different materials, different spinning methods should also be mentioned. While wet and melt spinning produce fibers with diameters in the micrometer range, electrospinning can be used to prepare nanofibers or complete nanofibrous mats. In crosslinked poly( $\varepsilon$-caprolactone) (PCL) nanofiber mats, contraction was found upon heating and relaxation upon cooling again, as depicted in Fig. 2 [48]. Cyclic thermomechanical tests showed reversible actuations around $22 \%$ for a strain of $300 \%$ and a pore size 
variation of $11 \%$ upon varying the temperature between $10^{\circ} \mathrm{C}$ and $60^{\circ} \mathrm{C}$. This relatively low variation on the microscale was attributed to the necessarily much larger changes on the macroscale.

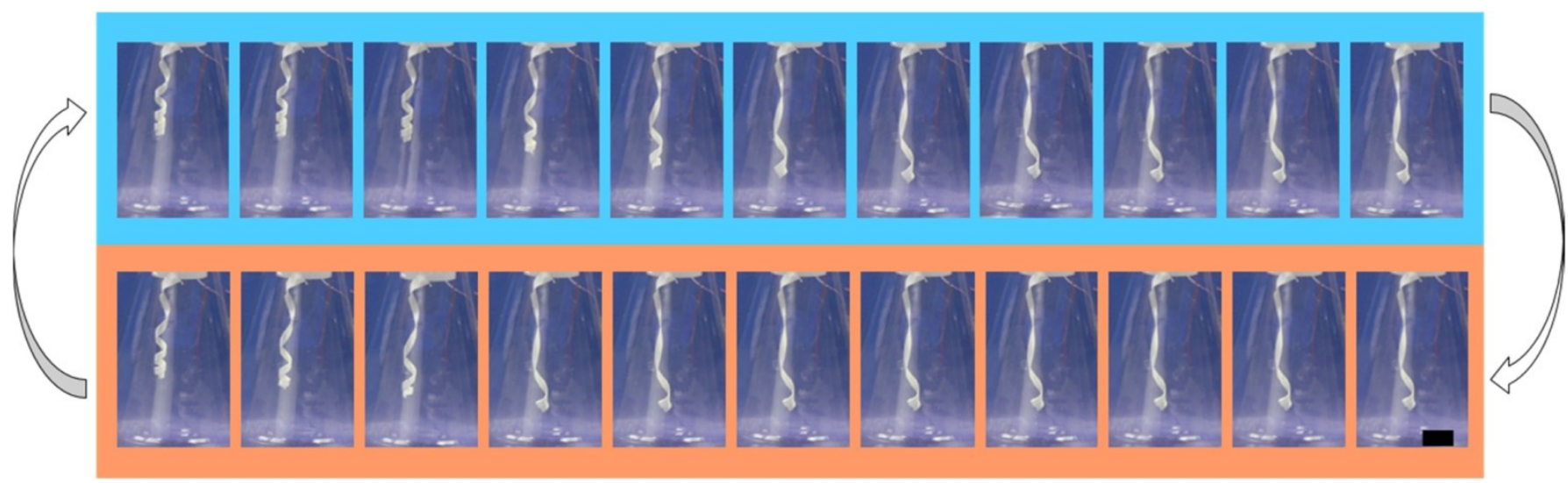

Fig. 2 Video images of sequential heating (orange) and cooling phases (blue) for a twisted specimen investigated in the range of $60^{\circ} \mathrm{C}-10^{\circ} \mathrm{C}$. The scale bar shows $2 \mathrm{~cm}$. From [48], originally published under a CC-BY license.

In crosslinked electrospun Nafion $®$ nanofiber mats with a small additional amount of poly(ethylene oxide) (PEO), Zhang et al. found even a shape memory effect with multiple shapes at different temperatures due to a broad transition temperature range from $60^{\circ} \mathrm{C}$ to $170{ }^{\circ} \mathrm{C}$ [49]. Combining PEO and PU, Feng et al. used coaxial electrospinning with crystalline PEO in the core and elastic PU in the shell to produce nanofibers with good shape recovery and temperature-dependent control of micro-pore structure and the

Besides the shape memory effect itself, another interesting property for several possible applications is the water vapor permeability, which was investigated by Zhuo et al. and found to decrease with an increase of the relative humidity and to increase with an increase in temperature [51].

As this short overview shows, there are diverse materials and spinning processes which allow producing shape memory fibers, yarns or nonwovens with varying shape memory properties for different applications. Nevertheless, spinning shape memory fibers from polymeric materials is not suitable for all situations. The next section thus describes examples of shape memory alloys integrate in textile fabrics in the form of wires or filaments.

\section{Shape memory textiles with integrated shape memory alloy wires}

Most production techniques for textile fabrics, such as weaving or weft knitting, as well as sewing and embroidery enable integrating thin wires or adding them to a textile fabric. By this method, e.g., fabrics from natural fibers, high-tenacity yarns etc. can obtain shape memory properties, although the base material does not show this effect [52].

The most basic integration of SMAs is on the yarn level. Chan Vili reported about integrating NiTi wires with diameters $0.2 \mathrm{~mm}$ and $0.3 \mathrm{~mm}$ as well as PU filaments of $0.15-0.35 \mathrm{~mm}$ into wrap spun yarns with different twists and other varying parameters [53]. She suggested using such yarns in diverse fabrics, applied for design purposes, for smart room partitions or smart curtains. Wang et al. [54] as well as Congalton [55] investigated the possibility to integrate SMA springs into thermal protective clothing, enabling modification of the air gap between the fabric layers. Similarly, Huang et al. suggested an integrated SMA wire into woven fabrics used as sleeves to shorten them upon heating up and elongating again when the environment becomes cooler [56], while SMA wires were integrated into knitted fabrics to enable new design aesthetics [57]. Special Origami techniques were used by Cabral et al. to design dynamic light filters, based on SMA wires integrated in woven fabrics [58], and Liu et al. applied Miuraorigami designs to prepare samples for compressive loading [59]. 
Salej Lah et al. investigated in detail the mechanical and shape memory properties of a Nitinol (Ni-Ti alloy) wire and demonstrated the influence of embedding it into a smart textile fabric [60]. Fig. 3 shows the different crystal phases of the Nitinol wire, triggered by heating and cooling, loading and unloading, as well as the corresponding effects on a textile fabric in which these wires are embedded.

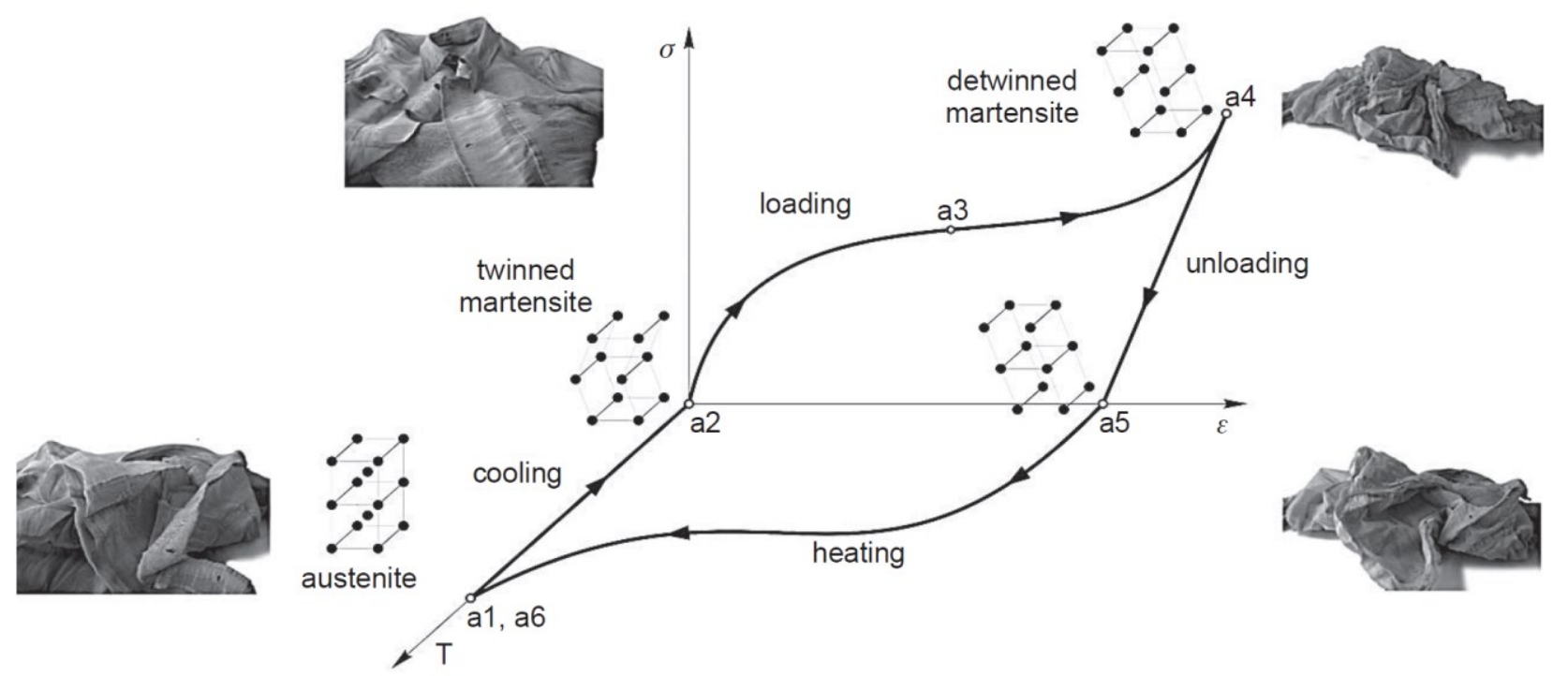

Fig. 2 Shape memory effect: example of shape changing of smart textile fabric with Nitinol filaments as function of stress $(\sigma)$, temperature $(T)$ and deformation $(\varepsilon)$. From [60], originally published under a CC-BY license.

Besides design applications, the aforementioned crinkle recovery belongs to the often reported reasons to include SMA wires in textile fabrics. Weinberg et al. showed that integration of a NiTi microfilament (diameter below $10 \mu \mathrm{m}$ ) into knitted textile fabrics led to superelastic recovery, and they suggested using such fabrics in addition for actuating and energy absorption [61]. To enable actuating by moving parts of smart fabrics over large distances, Helps et al. suggested embedding an SMA wire in a coiled guiding tube attached to the smart textile to overcome the problem of relatively small changes of the wire length upon heating [62].

Vasile et al., on the other hand, concentrated on the wrinkle recovery of woven fabrics with integrated SMA wires [63]. They mentioned the problem of SMA wire slippage inside the woven fabrics, depending on the combined yarns and the weaving parameters. Similarly, Vasile et al. investigated wrinkle recovery of flax fabrics in dry and wet conditions, comparing pure flax woven fabrics with hybrid fabrics including hybrid flax/SMA yarns and found significantly increase wrinkle recovery in the latter, which could be improved by optimizing the hybrid yarn structure [64,65].

Only few theoretical examinations of SMA/fabric hybrid textiles can be found in the literature. Holschuh and Newman developed a two-spring model to simulate the behavior of such hybrid textile in dependence from different design and material variables [66]. They found clear differences between spandex and neoprene fabrics on the one hand, showing linear response up to an elongation of $200 \%$, and polyester elastic as well as a tri-laminate Lycra on the other hand, showing nonlinear responses for these strains. Their main aim was modeling compression garments, which was enabled by a broad range of possible mechanical performances, depending on the design parameters.

Besides the integration of SMA wires into yarns or directly into textile fabrics, it is also possible to add SMPs to a textile fabric by coating or 3D printing. The next section shows examples of this approach.

\section{Shape memory textiles prepared by 4D printing or coating on fabrics}

While the so-called 4D printing belongs to the strongly investigated topics in the moment, 4D printing on textile fabrics is still scarce, possibly due to the often insufficient adhesion between both partners. 
Nevertheless, some attempts are reported in the literature, often making use of the interplay between relatively stiff imprinted polymers with shape memory effect and the soft, elastic fabric.

Leist et al., e.g., used the shape memory polymer PLA to print on nylon fabrics to train the composites thermo-mechanically into temporary forms and restore the original shape by heating them [67]. Khan and Hassan showed the process of preparing 4D textiles with a self-folding box as an example [68].

Zhang et al., on the other hand, interpreted the term "4D textiles" in another way [69]. They used 3D printing with PLA to mimic textile structures, here circular braided preforms, partly embedded in a silicone elastomer matrix, and found high recovery of nearly $100 \%$ in radial direction as well as circumferentially. This could be used to produce an "open" tube by cutting it along the longitudinal direction, flatten it and then use it as a gripper.

Combining 3D printing with embedded fibers in a single-step process, Wang et al. used a double nozzle conversion printer in which a carbon continuous fiber was impregnated by polyamide (PA) 6.6 in the nozzle before printing [70]. The final sample, however, consisted of one pure PA layer and another one with embedded carbon fibers, working similar to a common bi-metal sheet under the influence of heating the environment. This example shows that 4D printed textiles can also be prepared without using materials with shape memory properties.

A broad overview of the concepts of 4D textiles, often working with these multi-layer structures, was given by Schmelzeisen et al. [71] as well as Koch et al. [72], while Stapleton et al. concentrated on finiteelement modeling textiles with a printed polymeric grid on top, in which the textile fabrics were stretched during printing and which thus deformed after taking them off the printing bed into the final state [73].

The other aforementioned possibility to prepare shape memory fabrics is given by coating them with a shape memory polymer, such as polyurethane. Liem et al. combined PU with dimethyloldihydroxyethyleneurea (DMDHEU) as a fiber coating on cotton fabrics in order to reduce residual stress in the weft fibers [74]. The effect was attributed to balancing swelling due to moisture absorption by crosslinking between fibrils due to DMDHEU. Similarly, Liu et al. used this material combination for a wrinklerecovery coating [75].

A more plastic effect was aimed at by Jahid et al. who coated cotton fabrics with different PUs and found the finished fabric changing its permeability with temperature and humidity, in this way combining thermal insulation and water vapor transmission, depending on the environment [76]. The idea of this smart textile is illustrated in Fig. 3. A similar study was performed earlier by Mondal and $\mathrm{Hu}$ with a polyurethane coating [77] and recently on polyester with the same coating material [78].

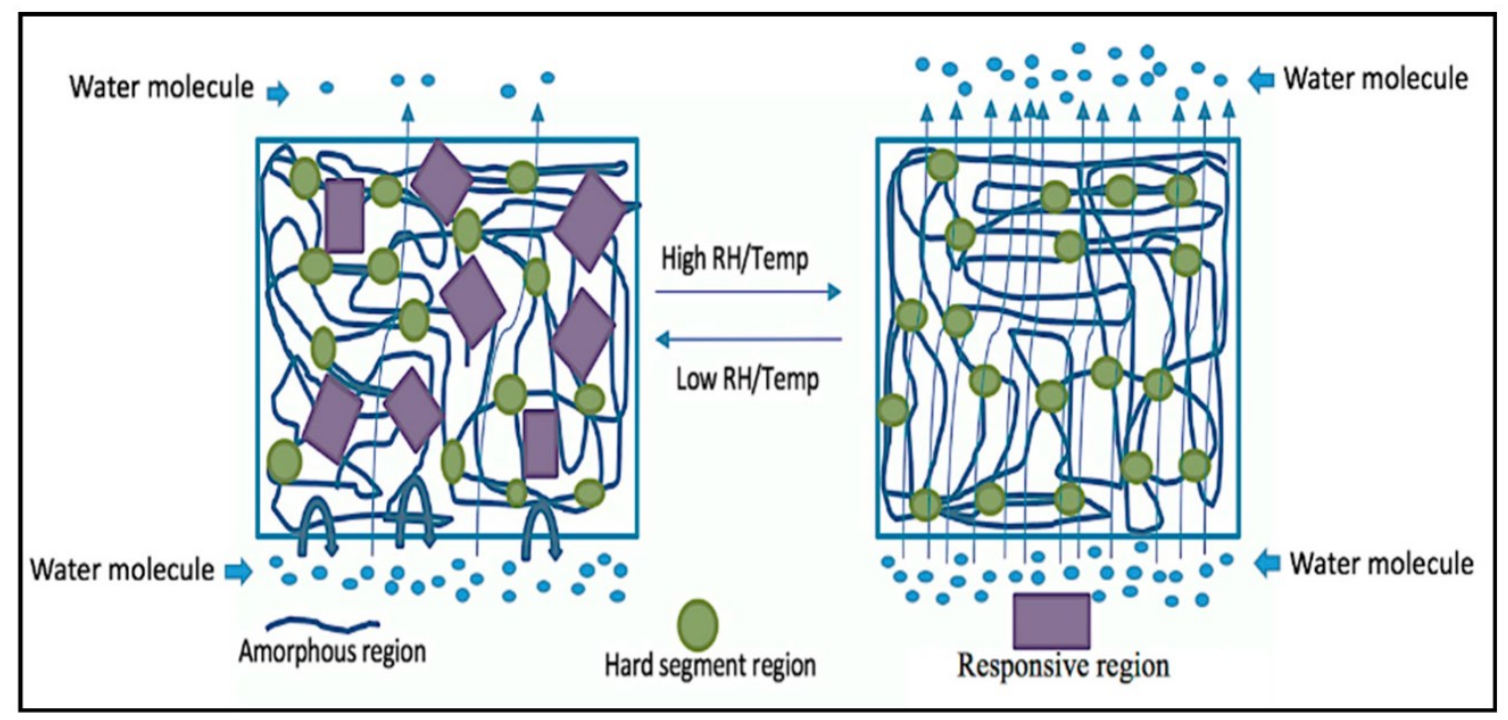

Fig. 3 Molecular design of responsive polyurethane. From [76], originally published under a CC-BY license. 


\section{Main applications of shape memory textiles}

Applications of shape memory textiles can be found in various areas. They can be used as actuators, making them highly interesting for soft robotics, where electric actuators can partly be replaced by shape memory materials driven by other stimuli $[6,7,62]$.

Similarly, applications in smart clothes are of high interest, where the possibility to change the dimensions or orientations of parts of the fabrics enables applying different pressure on the human body, useful from sports to wound care, opening or closing areas to modify air and water vapor permeability, or just producing clothes with high crinkle recovery $[8,9,32,35-37,60,76]$.

On the other hand, biomedical applications should be mentioned, where, e.g., stents can benefit from the possibility to be inserted into the body in a smaller shape and be extended at the desired position $[3,4,42]$.

Finally, shape memory textiles offer a broad range of new possibilities in textile and clothing design $[45,53,57]$.

\section{Conclusions}

Shape memory textiles can be produced from fibers with shape memory properties, by integrating shape memory allow wires or adding shape memory polymers by 3D printing or coating. In spite of the increasing number of studies on $4 \mathrm{D}$ printing in general, however, only a small number of publications reports on these possibilities to make textile fabrics smarter, offer a new freedom of design to them, or just make them more wrinkle-free by adding a shape memory effect.

However, there are still problems to overcome in order to reach all desired functionalities, such as too small dimensional changes, switching in only one direction due to an external stimulus, or insufficient fixture of an SMA wire in a textile fabric.

On the other hand, there are many more stimuli to be explored. Most of the shape memory materials used as fibers, as integrated wires or coatings recover due to thermal stimuli; only very few studies show recovery due to chemical stimuli (e.g. by a modified $\mathrm{pH}$ value) or upon illumination, showing the broad range of possible further investigations on shape memory textiles triggered by other stimuli.

While this review gives an overview of the already investigated possibilities to prepare and apply shape memory textiles, it also aims at motivating new investigations in this highly interesting field of research.

\section{References}

[1] Meng, Q. H.; Hu, J. L. A review of shape memory polymer composites and blends. Composites Part A: Applied Science and Manufacturing 2009, 40, 1661-1672. DOI: https://doi.org/10.1016/j.compositesa.2009.08.011

[2] Metcalfe, A.; Desfaits, A.-C; Salazkin, I.; Yahia, L'Hocine, Sokolowski, W. M.; Raymond, J. Cold hibernated elastic memory foams for endovascular interventions. Biomaterials 2003, 24, 491-497. DOI: https://doi.org/10.1016/S0142-9612(02)00362-9.

[3] Wache, H. M.; Tartakowska, D. J.; Hentrich, A.; Wagner, M. H. Development of a polymer stent with shape memory effect as a drug delivery system. Journal of Materials Science: Materials in Medicine 2003, 14, 109112. DOI: https://doi.org/10.1023/A:1022007510352.

[4] Yakacki, C.M.; Shandas, R.; Lanning, C.; Rech, B.; Eckstein, A.; Gall, K. Unconstrained recovery characterization of shape-memory polymer networks for cardiovascular applications. Biomaterials 2007, 28 , 2255-2263. DOI: https://doi.org/10.1016/j.biomaterials.2007.01.030.

[5] Blachowicz, T.; Pajak, K.; Recha, P.; Ehrmann, A. 3D printing for microsatellites - material requirements and recent developments. AIMS Mater. Sci. 2020, 7, 926-938. DOI: https://doi.org/10.3934/matersci.2020.6.926.

[6] Scalet, G. Two-way and multiple-way shape memory polymers for soft robotics: an overview. Actuators 2020, 9, 10. DOI: https://doi.org/10.3390/act9010010.

[7] Chen, Y.; Zhao, X.; Li, X.; Jin, Z.-Y.; Yang, Y.; Yang, M.-B.; Yin, B. Light- and magnetic-responsive synergy controlled reconfiguration of polymer nanocomposites with shape memory assisted self-healing performance 
for soft robotics. Journal of Materials Chemistry C 2021, 9, 5515-5527. DOI: https://doi.org/10.1039/D1TC00468A.

[8] Meng, Q.H.; Hu, J.L.; Yeung, L.Y. An electro-active shape memory fibre by incorporating multi-walled carbon nanotubes. Smart Mater. Struct. 2007, 16, 830-836. DOI: https://doi.org/10.1088/0964-1726/16/3/032.

[9] Gök, M. O.; Bilir, M. Z.; Gürcüm, B. H. Shape-memory applications in textile design. Procedia - Social and Behavioral Sciences 2015, 195, 2160-2169. DOI: https://doi.org/10.1016/j.sbspro.2015.06.283.

[10] Tobshi, H.; Hayashi, S.; Hoshio, K.; Miwa, N. Influence of strain-holding conditions on shape recovery and secondary-shape forming in polyurethane-shape memory polymer. Smart Materials and Structures 2006, 15, 1033. DOI: https://doi.org/10.1088/0964-1726/15/4/016.

[11] Lu, H. B.; Liu, Y. J.; Leng, J. S.; Du, S. Y. Qualitative separation of the physical swelling effect on the recovery behavior of shape memory polymer. European Polymer Journal 2010, 46, 1908-1914. DOI: https://doi.org/10.1016/j.eurpolymj.2010.06.013.

[12] Scirè Mammano, G.; Dragoni, E. Functional fatigue of Ni-Ti shape memory wires under various loading conditions. International Journal of Fatigue 2014, 69, 71-83. DOI: https://doi.org/10.1016/j.ijfatigue.2012.03.004.

[13] Ehrmann, G.; Ehrmann, A. 3D printing of shape memory polymers. Journal of Applied Polymer Science 2021, 138, 50847. DOI: https://doi.org/10.1002/app.50847.

[14] Tibbits, S. 4D Printing: Multi-Material Shape Change. Architectural Design 2014, 84, 116-121. DOI: https://doi.org/10.1002/ad.1710.

[15] Momeni, F.; Hassani.N, S. M. M.; Liu, X.; Ni, J. A review of 4D printing. Materials \& Design 2017, 122, $42-79$. DOI: https://doi.org/10.1016/j.matdes.2017.02.068.

[16] Champeau, M.; Heinze, D. A.; Viana, T. N.; Rodrigues de Souza, E.; Chinellato, A. C.; Titotto, S. 4D Printing of Hydrogels: A Review. Advanced Functional Materials 2020, 30, 1910606. DOI: https://doi.org/10.1002/adfm.201910606.

[17] Javaid, M.; Haleem, A. 4D printing applications in medical field: A brief review. Clinical Epidemiology and Global Health 2019, 7, 317-321. DOI: https://doi.org/10.1016/j.cegh.2018.09.007.

[18] Korger, M.; Glogowsky, A.; Sanduloff, S.; Steinem, C.; Huysman, S.; Horn, B.; Ernst, M.; Rabe, M. Testing thermoplastic elastomers selected as flexible three-dimensional printing materials for functional garment and technical textile applications. J. Eng. Fibers Fabrics 2020, 15, 1558925020924599. DOI: https://doi.org/10.1177/1558925020924599.

[19] Grimmelsmann, N.; Kreuziger, M.; Korger, M.; Meissner, H.; Ehrmann, A. Adhesion of 3D printed material on textile substrates. Rapid Prototyping J. 2018, 24(1), 166-170. DOI: https://doi.org/10.1108/RPJ-05-2016-0086.

[20] Mpofu, N. S.; Mwasiagi, J. I.; Nkiwane, L. C.; Njuguna, D. Use of regression to study the effect of fabric parameters on the adhesion of 3D printed PLA polymer onto woven fabrics. Fashion and Textiles 2019, 6, 24. DOI: https://doi.org/10.1186/s40691-019-0180-6.

[21] Calvo, J.O.; Martin, A.C.; Ferradas, M.I.R.; Morcillo, P.L.F.; Munoz, L.M.; Camo, P.M. Additive manufacturing on textiles with low-cost extrusion devices: Adhesion and deformation properties. Dyna 2019, 64, 8893. DOI: https://doi.org/10.6036/8893.

[22] Görmer, D.; Störmer, J.; Ehrmann, A. The influence of thermal after-treatment on the adhesion of 3D prints on textile fabrics. Communications in Development and Assembling of Textile Products 2020, 1, 104-110. DOI: https://doi.org/10.25367/cdatp.2020.1.p104-110.

[23] Senatov, F.S.; Zadorozhnyy, M.Y.; Niaza, K.V.; Medvedev, V.V.; Kaloshkin, S.D.; Anisimova, N.Y.; Kiselevskiy, M.V.; Yang, K.-C. Shape memory effect in 3D-printed scaffolds for self-fitting implants. Eur. Polym. J. 2017, 93, 222-231. DOI: https://doi.org/10.1016/j.eurpolymj.2017.06.011.

[24] Langford, T.; Mohammed, A.; Essa, K.; Elshaer, A.; Hassanin, H. 4D printing of origami structures for minimally invasive surgeries using functional scaffold. Applied Sciences 2021, 11, 332. DOI: https://doi.org/10.3390/app11010332.

[25] Ehrmann, G.; Brockhagen, B.; Ehrmann, A. Shape-memory properties of 3D printed cubes frm diverse PLA materials with different post-treatments. Technologies 2021, 9, 71. DOI: https://doi.org/10.3390/technologies9040071.

[26] Zhu, Y.; Hu, J. L.; Yeung, L.-Y.; Liu, Y.; Ji, F. L.; Yeung, K.-w. Development of shape memory polyurethane fiber with complete shape recoverability. Smart Materials and Structures 2006, 15, 1385. DOI: https://doi.org/10.1088/0964-1726/15/5/027.

[27] Singhal, P.; Small, W.; Cosgriff-Hernandez, E.; Maitland, D. J.; Wilson, T. S. Low density biodegradable shape memory polyurethane foams for embolic biomedical applications. Acta Biomaterialia 2014, 10, 67-76. DOI: https://doi.org/10.1016/j.actbio.2013.09.027.

[28] Zhao, T. T.; Yu, R.; Li, X. P.; Cheng, B.; Zhang, Y.; Yang, X.; Zhao, X. J.; Zhao, Y. L.; Huang, W. 4D printing of shape memory polyurethane via stereolithography. European Polymer Journal 2018, 101, 120-126. DOI: https://doi.org/10.1016/j.eurpolymj.2018.02.021.

[29] Gupta, V. B. Melt-spinning processes. In: Gupta, V. B.; Kothari, V. K. (eds.), Manufactured Fibre Technology. Springer, Dordrecht, 1997. DOI: https://doi.org/10.1007/978-94-011-5854-1_4. 
[30] Yalcinkaya, F. Preparation of various nanofiber layers using wire electrospinning system. Arabian Journal of Chemistry 2019, 12, 5162-5172. DOI: https://doi.org/10.1016/j.arabjc.2016.12.012.

[31] Dalton, P. D.; Grafahrend, D.; Klinkhammer, K.; Klee, D.; Möller, M. Electrospinning of polymer melts: Phenomenological observations. Polymer 2007, 48, 6823-6833. DOI: https://doi.org/10.1016/j.polymer.2007.09.037.

[32] Meng, Y. H.; Hu, J. L.; Zhu, Y.; Lu, J.; Liu, Y. Polycaprolactone-based shape memory segmented polyurethane fiber. Journal of Applied Polymer Science 2007, 106, 2515-2523. DOI: https://doi.org/10.1002/app.26764.

[33] Meng, Y. H.; Hu, J. L.; Zhu, Y.; Lu, J.; Liu, Y. Morphology, phase separation, thermal and mechanical property differences of shape memory fibres prepared by different spinning methods. Smart Materials and Structures 2007, 16, 1192. DOI: https://doi.org/10.1088/0964-1726/16/4/030.

[34] Meng, Q. H.; Hu, J. L.; Yeung, L. Y.; Hu, Y. The influence of heat treatment on the properties of shape memory fibers. II. Tensile properties, dimensional stability, recovery force relaxation, and thermomechanical cyclic properties. Journal of Applied Polymer Science 2009, 111, 1156-1164. DOI: https://doi.org/10.1002/app.29165.

[35] Kumar, B.; Hu, J. L; Pan, N. Smart medical stocking using memory polymer for chronic venous disorders. Biomaterials 2016, 75, 174-181. DOI: https://doi.org/10.1016/j.biomaterials.2015.10.032.

[36] Kumar, B.; Hu, J. L.; Pan, N. Memory bandage for functional compression management for venous ulcers. Fibers 2016, 4, 10. DOI: https://doi.org/10.3390/fib4010010.

[37] Kumar, B. Shape memory textiles for functional compression management. Veins and Lymphatics 2017, 6, 6633, 23-24. DOI: https://doi.org/10.4081/vl.2017.6633.

[38] Jing, L.; Hu, J. L. Study on the properties of core spun yarn and fabrics of shape memory polyurethane. FIBRES \& TEXTILES in Eastern Europe 2010, 18, 39-42.

[39] Ji, F. L.; Zhu, Y.; Hu, J. L.; Liu, Y.; Yeung, L.-Y.; Ye, G. D. Smart polymer fibers with shape memory effect. Smart Materials and Structures 2006, 15, 1547. DOI: https://doi.org/10.1088/0964-1726/15/6/006.

[40] Sáenz-Pérez, M.; Bashir, T.; Laza, J. M.; García-Barrasa, J.; Vilas, J. L.; Krifvars, M.; León, L. M. Novel shape-memory polyurethane fibers for textile applications. Textile Research Journal 2018, 89, 1027-1037. DOI: https://doi.org/10.1177/0040517518760756.

[41] Walczak, J.; Sobota, M.; Chrzanowski, M.; Krucinska, I. Application of the melt-blown technique in the production of shape-memory nonwoven fabrics from a blend of poly(L-lactide) and atactic poly[(R,S)-3-hydroxy butyrate]. Textile Research Journal 2018, 88, 2141-2152. DOI: https://doi.org/10.1177/0040517517716906.

[42] Meng, Q. H.; Hu, J. L.; Uhu, Y.; Lu, J.; Liu, B. H. Biological evaluations of a smart shape memory fabric. Textile Research Journal 2009, 79, 1522-1533. DOI: https://doi.org/10.1177/0040517509101789.

[43] Meng, Q. H.; Hu, J. L.; Zhu, Y. Shape-memory polyurethane/multiwalled carbon nanotube fibers. Journal of Applied Polymer Science 2007, 106, 837-848. DOI: https://doi.org/10.1002/app.26517.

[44] Deng, J.; Zhang, Y.; Zhao, Y.; Chen, P. N.; Cheng, X. L.; Peng, H. S. A shape-memory supercapacitor fiber. Angewandte Chemie - International Edition 2015, 54, 15419-15423. DOI: https://doi.org/10.1002/anie.201508293.

[45] Zhao, L. H.; Qin, L.; Wang, F. M.; Chuah, H. H. Factors affecting recovery of PTT shape memory fabric to its initial shape. International Journal of Clothing Science and Technology 2009, 21, 64-73. DOI: https://doi.org/10.1108/09556220910923764.

[46] Lu, X. K.; Chan, C. Y.; Lee, K. I.; Ng, P. F.; Fei, B.; Xin, J. H.; Fu, X. Super-tough and thermo-healable hydrogel - promising for shape-memory absorbent fiber. Journal of Materials Chemistry B 2014, 2, 7631-7638. DOI: https://doi.org/10.1039/C4TB01289E.

[47] Zhu, K. K.; Wang, Y.; Lu, A.; Fu, Q.; Hu, J. L.; Zhang, L. Cellulose/Chitosan Composite Multifilament Fibers with Two-Switch Shape Memory Performance. ACS Sustainable Chemistry \& Engineering 2019, 7, 69816990. DOI: https://doi.org/10.1021/acssuschemeng.8b06691.

[48] Zhang, Q. C.; Rudolph, T.; Benitez, A. J.; Gould, O. E. C.; Behl, M.; Kratz, K.; Lendlein, A. Temperaturecontrolled reversible pore size change of electrospun fibrous shape-memory polymer actuator based meshes. Smart Materials and Structures 2019, 28, 055037. DOI: https://doi.org/10.1088/1361-665X/ab10a1.

[49] Zhang, F. H.; Zhang, Z. C.; Liu, Y. J.; Lu, H. B.; Leng, J. S. The quintuple-shape memory effect in electrospun nanofiber membranes. Smart Mater. Struct. 2013, 22, 085020. DOI: https://doi.org/10.1088/0964$1726 / 22 / 8 / 085020$.

[50] Feng, W.; Zhang, Y.-s.; Shao, Y.-w.; Huang, T.; Zhang, N.; Yang, J.-h.; Qi, X.-d.; Wang, Y. Coaxial electrospun membranes with thermal energy storage and shape memory functions for simultaneous thermal/moisture management in personal cooling textiles. European Polymer Journal 2021, 145, 110245. DOI: https://doi.org/10.1016/j.eurpolymj.2020.110245.

[51] Zhuo, H. T.; Hu, J. L.; Chen, S. J. Study of water vapor permeability of shape memory polyurethane nanofibrous nonwovens. Textile Research Journal 2011, 81, 883-891. DOI: https://doi.org/10.1177/0040517510392469. 
[52] Dyer, P. Integration of small diameter wire form SMA for the creation of dynamic shape memory textiles. Advances in Science and Technology 2012, 80, 53-58. DOI: https://doi.org/10.4028/www.scientific.net/AST.80.53.

[53] Chan Vili, Y. Y. F. Investigating smart textiles based on shape memory materials. Textile Research Journal 2007, 77, 290-300. DOI: https://doi.org/10.1177/0040517507078794.

[54] Wang, L. J.; Lu, Y. H.; He, J. Z. On the effectiveness of temperature-responsive protective fabric incorporated with shape memory alloy (SMA) under radiant heat exposure. Clothing and Textiles Research Journal 2020, 38, 212-224. DOI: https://doi.org/10.1177/0887302X19892095.

[55] Congalton, C. Shape memory alloys for use in thermally activated clothing, protection against flame and heat. Fire and Materials 1999, 23, 223-226. DOI: https://doi.org/10.1002/(SICI)10991018(199909/10)23:5<223::AID-FAM687>3.0.CO;2-K.

[56] Huang, Y.; Zhu, M. S.; Pei, Z. X.; Xue, Q.; Huang, Y.; Zhi, C. Y. A shape memory supercapacitor and its application in smart energy storage textiles. Journal of Materials Chemistry A 2016, 4, 1290-1297. DOI: https://doi.org/10.1039/C5TA09473A.

[57] Winchester, R. C. C.; Stylios, G. K. Designing knitted apparel by engineering the attributes of shape memory alloy. International Journal of Clothing Science and Technology 2003, 15, 359-366. DOI: https://doi.org/10.1108/09556220310492624.

[58] Cabral, I.; Souto, A. P.; Carvalho, H.; Cunha, J. Exploring geometric morphology in shape memory textiles: design of dynamic light filters. Textile Research Journal 2015, 85, 1919-1933. DOI: https://doi.org/10.1177/0040517515578328.

[59] Liu, Y.; Zhang, W.; Zhang, F. h.; Land, X.; Leng, J. S.; Liu, S.; Jia, X. Q.; Cotton, C.; Sun, B. Z.; Gu, B. H.; Chou, T.-W. Shape memory behavior and recovery force of 4D printed laminated Miura-origami structures subjected to compressive loading. Composites Part B: Engineering 2018, 153, 233-242. DOI: https://doi.org/10.1016/j.compositesb.2018.07.053.

[60] Salej Lah, A.; Fajfar, P.; Lavric, Z.; Bukosek, V.; Rijavec, T. Preparation of shape memory NiTiNOL filaments for smart textiles. Tekstilec 2016, 59, 168-174. DOI: https://doi.org/10.14502/Tekstilec2016.59.168-174.

[61] Weinberg, C. A.; Cai, S.; Schaffer, J.; Abel, J. Multifunctional spun yarns and textiles from nickel-titanium microfilaments. Advanced Materials Technologies 2020, 5, 1901146. DOI: https://doi.org/10.1002/admt.201901146.

[62] Helps, T.; Vivek, A.; Rossiter, J. Characterization and Lubrication of Tube-Guided Shape-Memory Alloy Actuators for Smart Textiles. Robotics 2019, 8, 94. DOI: https://doi.org/10.3390/robotics8040094.

[63] Vasile, S.; Grabowska, K. E.; Ciesielska-Wróbel, I. L.; Githaiga, J. Analysis of hybrid woven fabrics with shape memory alloys wires embedded. FIBRES \& TEXTILES in Eastern Europe 2010, 18, 64-69.

[64] Vasile, S.; Githaiga, J.; Ciesielska-Wróbel, I. L. Comparative analysis of the mechanical properties of hybrid yarns with superelastic shape memory alloys (SMA) wires embedded. FIBRES \& TEXTILES in Eastern Europe 2011, 19, 41-46.

[65] Vasile, S.; Ciesielska-Wróbel, I. L.; van Langenhove, L. Wrinkle recovery of flax fabrics with embedded superelastic shape memory alloys wires. FIBRES \& TEXTILES in Eastern Europe 2012, 20, 56-61.

[66] Holschuh, B.; Newman, D. Two-spring model for active compression textiles with integrated NiTi coil actuators. Smart Materials and Structures 2015, 24, 035011. DOI: https://doi.org/10.1088/0964$1726 / 24 / 3 / 035011$.

[67] Leist, S. K.; Gao, D. J.; Chiou, R.; Zhou, J. Investigating the shape memory properties of 4D printed polylactic acid (PLA) and the concept of 4D printing onto nylon fabrics for the creation of smart textiles. Virtual and Physical Prototyping 2017, 12, 290-300. DOI: https://doi.org/10.1080/17452759.2017.1341815.

[68] Khan, Md. K. R.; Hassan, Md. N. Understanding the concept of 4D textiles. South Asian Research Journal of Engineering and Technology 2021, 3, 93-95. DOI: https://doi.org/10.36346/sarjet.2021.v03i03.005.

[69] Zhang, W.; Zhang, F. H.; Lan, X.; Leng, J. S.; Wu, A. S.; Bryson, T. M.; Cotton, C.; Gu, B. H.; Sun, B. Z.; Chou, T.-W. Shape memory behavior and recovery force of 4D printed textile functional composites. Composites Science and Technology 2018, 160, 224-230. DOI: https://doi.org/10.1016/j.compscitech.2018.03.037.

[70] Wang, Q. R.; Tian, X. Y.; Huang, L.; Li, D. C.; Malakhov, A. V.; Polilov, A. N. Programmable morphing composites with embedded continuous fibers by 4D printing. Materials \& Design 2018, 155, 404-413. DOI: https://doi.org/10.1016/j.matdes.2018.06.027.

[71] Schmelzeisen, D.; Koch, H.; Pastore, C.; Gries, T. 4D textiles: hybrid textile structures that can change structural form with time by 3D printing. In: Kyosev, Y.; Mahltig, B.; Schwarz-Pfeiffer, A. (eds.) Narrow and Smart Textiles, 2018, 189-201. Springer, Cham. DOI: https://doi.org/10.1007/978-3-319-69050-6_17.

[72] Koch, H. C.; Schmelzeisen, D.; Gries, T. 4D textiles made by additive manufacturing on pre-stressed textiles an overview. Actuators 2021, 10, 31. DOI: https://doi.org/10.3390/act10020031.

[73] Stapleton, S. E.; Kaufmann, D.; Krieger, H.; Schenk, J.; Gries, T.; Schmelzeisen, D. Finite element modeling to predict the steady-state structural behavior of 4D textiles. Textile Research Journal 2019, 89, 3484-3498. DOI: https://doi.org/10.1177/0040517518811948. 
[74] Liem, H.; Yeung, L. Y.; Hu, J. L. A prerequisite for the effective transfer of the shape-memory effect to cotton fibers. Smart Materials and Structures 2007, 16, 748. DOI: https://doi.org/10.1088/0964-1726/16/3/023.

[75] Liu, X. X.; Hu, J. L.; Babu, K. M.; Wang, S. Y. Elasticity and Shape Memory Effect of Shape Memory Fabrics. Textile Research Journal 2008, 78, 1048-1056. DOI: https://doi.org/10.1177/0040517508087854.

[76] Jahid, Md. A.; Hu, J. L.; Wong, K. H.; Wu, Y.; Zhu, Y.; Luo, H. H. S.; Zhongmin, D. Fabric coated with shape memory polyurethane and its properties. Polymers 2018, 10, 681. DOI: https://doi.org/10.3390/polym10060681.

[77] Mondal, S.; Hu, J. L. Water vapor permeability of cotton fabrics coated with shape memory polyurethane. Carbohydrate Polymers 2007, 67, 282-287. DOI: https://doi.org/10.1016/j.carbpol.2006.05.030.

[78] Korkmaz Memis, N.; Kaplan, S. Smart polyester fabric with comfort regulation by temperature and moisture responsive shape memory nanocomposite treatment. Journal of Industrial Textiles 2020, online first. DOI: https://doi.org/10.1177/1528083720975652. 